\title{
EL LUCRO EN LAS PERSONAS JURÍDICAS: COMENTARIO A LA SENTENCIA DE LA EXCELENTÍSIMA CORTE SUPREMA, EN LOS AUTOS CARATULADOS: FUNDACIÓN SOLIDARIDAD CON SERVICIO DE IMPUESTOS INTERNOS, ROL No 991-2015
}

\author{
PROFITS IN LEGAL ENTITIES: COMMENT TO THE JUDGMENT \\ OF THE SUPREME COURT EXCELLENCY, IN RE: FOUNDATION \\ SOLIDARITY WITH INTERNAL REVENUE SERVICE, ROL NO. 991-2015
}

\section{Eduardo Iribarra Sobarzo*}

\begin{abstract}
RESUMEN: Este artículo analiza el actual concepto de lucro en las personas jurídicas por la Excelentísima Corte Suprema, específicamente, en una fundación de derecho público. Critica su razonamiento, a partir de la norma de tasación del artículo 35 de la Ley sobre Impuesto a la Renta, de que la ganancia obtenida por esta entidad en virtud del desarrollo de una actividad económica, no constituye lucro, en atención a que tales recursos se destinan exclusivamente a sus propios fines benéficos.
\end{abstract}

Palabras clave: Lucro, fundación, corporación, tasación, persona jurídica

ABSTRACT: This paper reviews a Supreme Court's judgment regarding the current notion of profit in legal entities, specifically in case of a public nonprofit organization. Based on the tax assessment rule of Article 35 of the Income Tax Law, this paper criticizes the Court's reasoning that earnings obtained by this kind of entity in the development its business activity do not qualify as revenue based on the fact they are exclusively destined to charitable purposes.

Key words: Profit, nonprofit organization, tax assessment, legal entity

\section{INTRODUCCIÓN}

En los últimos lustros, hemos sido testigos de la proliferación en Chile de las organizaciones sin fines de lucro. Esta especial expresión de los grupos intermedios, en conjunto con el auge del cooperativismo, ha dado cuenta del reconocimiento en la sociedad contemporánea del valor de la solidaridad como condición necesaria para la justicia social, aspecto que fuere soslayado en buena parte por la actual Constitución Política de la República ${ }^{1}$.

\footnotetext{
* Abogado, magíster en tributación Universidad de Chile, doctorado en Derecho Universidad de los Andes, Chile. Dirección postal: Monseñor Álvaro del Portillo No 12455, Las Condes, Región Metropolitana, Chile. Dirección electrónica: eiribarrasobarzo@gmail.com

1 Constitución Política de la República de Chile de 1980.
} 
La utilidad de estas organizaciones como instrumento de la voluntad humana individual y colectiva es diversa e incluso inabarcable, pues alcanza incluso fines económicos. Además, estas entidades han resultado interesantes como instrumentos de ahorro tributario e incluso de elusión por algunos contribuyentes, en consideración a las ventajas que las normas tributarias les han ido concediendo con los años.

Pues bien, el alcance del fin económico que la ley permite desarrollar a las personas jurídicas sin fines de lucro, parece no haber sido esclarecido del todo entre la doctrina y jurisprudencia chilenas, pues ha sido confrontado con un erróneo sentido y alcance del fin no lucrativo al que se encuentran sometidas. Y justamente una sentencia reciente de la Excelentísima Corte Suprema (que conoce de un recurso de casación en el fondo interpuesto en contra de una sentencia de la Corte de Apelaciones de Santiago, confirmatoria de la del Tribunal Tributario y Aduanero de Santiago [TTA]) ${ }^{2}$ trata sobre dicho conflicto, mediante una singular noción de lucro respecto de estas entidades, que no se corresponde con un significado que reconozca sus características especiales. Asimismo, en esta sentencia se asume una diferencia irreconciliable entre el lucro obtenido por una empresa y el obtenido por una fundación, con efectos negativos para la eficiencia de las normas tributarias, y especialmente, de la Ley sobre Impuesto a la Renta (LIR) ${ }^{3}$.

La sentencia señalada, permitirá indagar en este artículo sobre una correcta definición de la condición de no lucrativas de las fundaciones y corporaciones, tomando en cuenta, entre otros aspectos, el alcance de las limitaciones legales a la que se encuentran sujetas, y su facultad para desarrollar actividades económicas, incluso lucrativas.

\section{LA SENTENCIA}

El fallo versa sobre la procedencia de equiparar dos entidades que realizaban una misma actividad económica, con la particularidad de que una de ellas es una empresa con fines lucrativos, y la otra, una fundación de derecho público (en adelante también, la "Fundación"). Admitir la equiparación señalada resultaba fundamental para la aplicación por parte del Servicio de Impuestos Internos (SII, o el Servicio), de la norma de tasación contenida en el artículo 35 de la Ley sobre Impuesto a la Renta, cuya hipótesis normativa es la siguiente: "Cuando la renta líquida imponible no pueda determinarse clara y fehacientemente, por falta de antecedentes o cualquiera otra circunstancia, se presume que la renta mínima imponible de las personas sometidas al impuesto de esta categoría es igual al 10\% del capital efectivo invertido en la empresa o a un porcentaje de las ventas realizadas durante el ejercicio, el que será determinado por la Dirección Regional, tomando como base, entre otros antecedentes, un promedio de los porcentajes obtenidos por este concepto o por otros contribuyentes que giren en el mismo ramo o en la misma plaza. Corresponderá, en cada caso, al Director Regional, adoptar una u otra base de determinación de la renta".

Con ocasión de las facultades de fiscalización, el Servicio de Impuestos Internos detectó que la Fundación había realizado una actividad económica generadora de rentas, por las cuales no había cumplido con el pago del Impuesto de Primera Categoría. En razón de ello, el Servicio emitió una liquidación de impuestos a dicha entidad, determinando el Impuesto de Primera Categoría de acuerdo a la norma citada, sobre la base consistente en

\footnotetext{
2 FundaCión Solidaridad CON SERVICIO de Impuestos Internos (2016)

3 Decreto Ley No 824 de 1974
} 
un promedio de ventas obtenidas por otros contribuyentes que giraban en el mismo ramo. Para ello, se valió de contribuyentes que realizaban la misma actividad artesanal que la fundación, pero que tenían fines de lucro. Según se expresa en la sentencia en análisis, el Servicio justificó dicha medida, en atención a que lo único que exige la norma señalada, es que los contribuyentes con los cuales se compare y se haga la tasación sean del mismo ramo o en la misma plaza, "de lo cual resulta manifiesto que la circunstancia de ser o no un contribuyente con fines de lucro, no resulta ser un parámetro legalmente exigible para la aplicación de dicha tasación" ${ }^{\text {. }}$. Con ello -aducía el Servicio-, se ha inobservado la regla de interpretación "que obliga a no desatender el tenor literal de las normas, cuando su sentido sea claro según dispone el artículo 19 inciso primero del Código Civil"'. Insistía el Servicio en que la norma en cuestión busca "otorgar el mismo tratamiento tributario a contribuyentes que obtienen sus ingresos dentro del mismo rubro o actividad comercial desarrollada y dentro de una misma zona geográfica, lo que no implica (...) que se pretenda comparar contribuyentes de condiciones idénticas, pues no es ese el sentido de la norma"6.

El argumento más importante sostenido por el Servicio en el recurso de casación interpuesto, consistió en objetar la afirmación del juez del TTA de que los contribuyentes tomados como comparables por el Servicio no tienen relación alguna con la fundación reclamante, porque el ánimo de lucro o su ausencia, "marca una diferencia fundamental que transforma a los contribuyentes con parámetros difíciles de homologar" cio, "las corporaciones y fundaciones pueden tener utilidades y no por la sola circunstancia de no tener fines de lucro, sus rentabilidades necesariamente van a ser distintas de las empresas con fines de lucro que ejerzan la misma actividad; por lo cual considerar el ánimo de lucro como único elemento diferenciador, resulta un razonamiento erróneo efectuado sobre un hecho asentado en el juicio, lo que importa una vulneración de la regla de lógica de la razón suficiente" ${ }^{\prime}$, esto es, que la ley siempre tiene una razón.

En sus consideraciones, la Corte Suprema adhiere a la tesis de que las corporaciones y fundaciones de beneficencia pública, se definen como aquella que sin ánimo de lucro, tiene por finalidad hacer el bien, sea este de orden intelectual, moral o material. Afirma la sentencia que "el comparar talleres artesanales con fines de lucro con la Fundación que no lo tiene, es una diferencia fundamental que transforma a los contribuyentes con parámetros difíciles de homologar" . Continúa afirmando la Corte que "La fundación reclamante de acuerdo a la prueba aportada al proceso, pretendía ayudar a ciertas personas, en la capacitación y posterior comercialización de las artesanías producidas, financiándose básicamente gracias a donaciones que recibía. De la producción y comercialización propiamente tal de sus productos el margen era mínimo, y solo alcanzó para su supervivencia y para el cumplimiento de sus fines durante algunos años. Es necesario destacar para que se entienda lo alejada del lucro que estaba, que la fundación formaba parte de la Vicaría de la Solidaridad y estaba a cargo de la asesoría, capacitación y comercialización de talleres artesanales como respuesta a las necesidades de las miles de personas en prisión o sus familias en situación de

\footnotetext{
Considerando Primero de la sentencia.

Considerando Primero de la sentencia.

Considerando Primero de la sentencia.

Considerando Primero de la sentencia.

8 Considerando Primero de la sentencia.

9 Considerando Quinto de la sentencia.
} 
extrema pobreza y que a través de las arpilleras de la solidaridad, fue un relato de las penurias que sufrieron las madres y cónyuges que buscaban con angustia a sus seres queridos, detenidos o desaparecidos. Es por esto, que el concepto de lucro para esta organización, solo giraba en torno a lo necesario para proveer de materiales a más familias y en cierta forma poder ayudar con la venta de las mismas; no se pretendía obtener ganancias para lucrar, lo que sí persiguen los demás talleres artesanales, ya que es su fuente de sustento; es por esto que el comparar fundaciones con y sin fines de lucro no resulta homologable. Tanto así es, que la máxima rentabilidad obtenida por la Fundación alcanzó un 9\% mientras que los talleres artesanales con los cuales el Servicio de Impuestos Internos hizo la comparación alcanzaban un $61 \%$, lo anterior no hace más que demostrar que no es posible comparar esta fundación con talleres artesanales con fines de lucro" ${ }^{10}$. En virtud de lo razonado por la Corte, esta afirma al final de su sentencia que "la facultad establecida en favor de la administración tributaria -se refiere a la de tasar contenida en el artículo 35 de la LIR-, supone o tiene implícito el requisito, que los contribuyentes con que se obtiene el promedio y que giren en la misma actividad o en la misma plaza, tienen que ser parecidos, equivalentes o comparables y de acuerdo a lo señalado anteriormente no lo es si comparamos instituciones con o sin fines de lucro, justamente para establecer las ganancias de ellas"11.

\section{EL LUCRO EN LAS FUNDACIONES Y CORPORACIONES}

El Título XXXIII del Libro I del Código Civil regula a las personas jurídicas, distinguiéndolas entre corporaciones y fundaciones de beneficencia pública. En seguida, el artículo 547 del Código excluye de su regulación a las sociedades industriales, y a las corporaciones o fundaciones de derecho público, cada una de las cuales se rigen por sus normas especiales $^{12}$. La ley ejemplifica a las corporaciones o fundaciones de derecho público con la nación, el fisco, las municipalidades, las iglesias, comunidades religiosas, y los establecimientos que se costean con fondos del erario.

Es importante señalar que la sentencia no distinguió que la Fundación liquidada por el Servicio consistía en una fundación de derecho público ${ }^{13}$, por lo que se encontrarían excluidas de la regulación contemplada en el Título XXXIII del Libro I del Código Civil. En su caso, sus normas se encuentran en la Ley N. 19.638 que establece normas sobre la constitución jurídica de las iglesias y organizaciones religiosas, en cuyo artículo 9 inciso segundo, se dispone que las entidades religiosas, así como las personas jurídicas que ellas constituyan "no podrán tener fines de lucro".

En cuanto a los fines de las corporaciones y fundaciones que regula el Título XXXIII del Libro I del Código Civil, modificadas por la Ley No 20.500 de 2011, su artículo 545 inciso tercero dispone que la asociación "se forma por una reunión de personas en torno

\footnotetext{
10 Considerando Quinto de la sentencia.

11 Considerando Quinto de la sentencia.

12 Con todo, la exclusión a las entidades singularizadas, no impediría considerar a las normas del Código Civil como normas supletorias, atendido su carácter de derecho común.

13 La fundación involucrada en el juicio en estudio, parece ser de aquellas denominadas "asociaciones públicas de fieles". Un interesante estudio sobre la personalidad jurídica de las entidades religiosas católicas tales como las diócesis, iglesias particulares, y asociaciones de fieles, en BERTELSEN (1991) pp. 473-484.
} 
a objetivos de interés común a los asociados". De la definición, se desprende claramente que tales objetivos no son de interés general, sino de interés particular, pues atiende al beneficio directo de sus asociados, beneficio que no es solo ideal, sino que en muchos casos se manifiesta en beneficios materiales o avaluables en dinero. Así, es posible constituir una asociación para fines de ahorro y préstamo entre sus asociados, para asegurar contingencias económicas de sus miembros, para la capacitación, fomento de actividades empresariales, colaboración gremial, cultura, etc. En tales casos, el asociado de una de estas corporaciones, podría ser beneficiario de bienes o servicios en condiciones económicamente más ventajosas que si las adquiriera o contratara en forma directa.

Por su parte, la fundación, a diferencia de la corporación, se define como aquella entidad formada "mediante la afectación de bienes a un fin determinado de interés general". Este tipo de entidad, resulta de una alternativa a la propiedad fiduciaria, a las donaciones o asignaciones testamentarias. Su definición parece denotar la imposibilidad de constituir una fundación para el beneficio particular de un grupo, como parece señalarlo Alessandri, cuando sostiene que las fundaciones "tienen como destinatarios a todos en general" 14 , esto es, a personas indeterminadas. Sin embargo, tal afirmación no es correcta, si se distingue entre el fin de interés general que el fundador ha concebido en la creación de una fundación (como sería, por ejemplo, la educación, asistencia social o las ciencias), de los beneficiarios o destinatarios de los recursos afectados para tales fines, estos últimos, que admiten una propia clasificación, a saber, quienes aprovechen los bienes o servicios ofrecidos por una fundación, los cuales pueden o no ser indeterminados (i.e. los asistentes a un museo del arte de acceso gratuito, o los niños de un determinado colegio), y quienes sean financiados para desarrollar las actividades que se enmarcan en los fines de interés general, estos últimos que requieren ser determinados o determinables (i.e. los artistas, profesionales, científicos o estudiantes, una universidad, que se dedicarán a realizar las actividades concebidas por el fundador). Es decir, los beneficiarios de los recursos de una fundación, no solo lo serán las personas que recibirán los bienes o servicios, sino también aquellos que son llamados a proporcionarlos o prestarlos mediante una remuneración. En el caso de las fundaciones, incluso el mismo fundador podría constituirse como uno de los beneficiarios del último orden señalado, como ocurriría si aquel fuese un médico, y recibiere una remuneración de la fundación, para que se dedique a la atención gratuita a determinado grupo de personas. Como puede apreciarse, es equivocada la concepción de que los beneficiarios de una fundación deben ser indeterminados, según se explicó, sin perjuicio de que indirectamente pueda serlo, cuando una fundación contribuya al mejoramiento, por ejemplo, de la cultura, ciencia o arte de un país.

En cuanto al adjetivo de las fundaciones de que sean de "beneficencia pública", es necesario señalar que tal enunciado es distinto de la "caridad", puesto que por beneficencia pública debe entenderse como la acción de hacer el bien a los demás, y este puede importar acciones caritativas (i.e. mantener una casa de ancianos), o no (i.e. destinarse a la investigación científica) ${ }^{15}$. Por su parte, es acertada la explicación entre fundaciones o corporaciones

14 Alessandri et al. (2009) Tomo I, p. 542.

15 Alessandri et al. (2009) Tomo I, p. 542. 
de derecho público y privado, en atención a la fuente de su existencia, siendo públicas aquellas constituidas por las leyes, en tanto que las privadas, de la iniciativa de los particulares ${ }^{16}$. Sin embargo, la doctrina ha adoptado otros criterios para diferenciar entre entidades públicas o privadas.

La especificación de los beneficiarios en las fundaciones y corporaciones reguladas en el Código Civil, también es una exigencia legal, pues su artículo 548-2 manda que los estatutos de estas entidades contengan reglas básicas para la determinación de los beneficiarios. La elección de los destinatarios de tales recursos, queda reservada exclusivamente a los asociados o al fundador.

Hasta ahora se han definido los contornos de las definiciones puras de fundaciones y corporaciones reguladas en el Título XXXIII del Libro I del Código Civil. Sin embargo, el inciso cuarto del artículo 545 del cuerpo legal referido dispone que "hay personas jurídicas que participan de uno y otro carácter”, entendiendo carácter como aquellas cualidades propias de algo ${ }^{17}$. De tal norma, se desprendería la autorización para constituir una asociación para un fin determinado de interés general, o bien una fundación con un objetivo de interés particular, como serían las fundaciones familiares, reconocidas en otras legislaciones. $\mathrm{Al}$ respecto, no se ve inconveniente para combinar ambas instituciones, incluso por aplicación directa de normas constitucionales ${ }^{18}$, como el derecho a desarrollar cualquier actividad económica, el derecho de propiedad, o bien apoyándose en el principio de autonomía de la voluntad. Por lo demás, es innegable que por más que sea específico y acotado el beneficio buscado en la creación de una entidad como las tratadas, siempre existirá algún grado de beneficio general, que trasciende a los beneficiarios individualizados.

A mayor abundamiento, la misma Corte Suprema reconoció en una sentencia del año 1908 que "las personas jurídicas de derecho privado no están llamadas a realizar los fines propios de los poderes públicos, sino a cumplir las aspiraciones personales de los mismos asociados o las de los fundadores" ${ }^{19}$.

De lo dicho, es posible afirmar primeramente que el fin de las corporaciones y fundaciones puede ser de interés general o particular, y que la determinación de los beneficiarios no es un impedimento infranqueable, menos aún en el caso de las corporaciones. Específicamente en el caso de las fundaciones, cuando el fin sea de interés general, ello no significa que necesariamente los beneficiarios sean indeterminados, según se señaló.

Por otro lado, tanto en las corporaciones como en las fundaciones, los destinatarios, cualesquiera que sean estos, no obstante beneficiarse moralmente de los fines de las corporaciones o fundaciones, necesariamente son objeto de algún grado de beneficio económico, pues de alguna manera acceden a bienes o servicios a un precio más ventajoso. Esta circunstancia inevitablemente implica un beneficio económico directo o indirecto, experimentando en algún grado un incremento patrimonial o ganancia, pues los beneficios económicos

16 Claro (2013) Tomo II, p. 424.

17 Según la definición entregada por el Diccionario de la Real Academia Española (RAE).

18 Sobre la aplicación de normas constitucionales para la resolución de asuntos de derecho privado, CorRAL (2014) pp. 1-16.

19 Sentencia citada por Claro (2013) Tomo II, p. 424. 
no solo se miden por la adquisición o posesión de recursos monetarios o de bienes, sino también por el acceso a bienes privados o públicos, o bien a servicios, a precios más ventajosos o bien gratuitos. Ahora, el beneficio económico antedicho no constituye la razón de existencia de las fundaciones o corporaciones, sino más bien la consecuencia de haber participado en la concreción de los fines generales o particulares concebidos en la constitución de estas entidades.

Ahora bien, el beneficio moral e inmaterial obtenido por los beneficiarios de las fundaciones y corporaciones, puede provenir no solo de la gestión efectuadas por las personas interesadas en cumplir sus fines, sino que en gran medida por los recursos o patrimonio de que dispongan. Este patrimonio no solo se constituye de los aportes fundacionales, los efectuados durante la vigencia de la entidad, o los recibidos a cualquier título, sino también mediante las ganancias provenientes de la enajenación de sus bienes, y en especial, del desarrollo de actividades económicas lucrativas. Al menos en el caso de las personas reguladas por el Título XXXIII del Libro I del Código Civil, ello es permitido, en la medida de que las actividades económicas se relacionen con sus fines. En efecto, el artículo 557-2 del Código Civil señala que "las asociaciones y fundaciones podrán realizar actividades económicas que se relacionen con sus fines. Asimismo, podrán invertir sus recursos de la manera que decidan sus órganos de administración”. En el caso de las personas jurídicas reguladas en la Ley No 19.638, como es el caso de la Fundación, no es posible encontrar la misma norma citada. Únicamente su artículo 14 dispone que la "administración de los bienes necesarios para las actividades de las personas jurídicas constituidas conforme a esta ley estarán sometidas a la legislación común”, lo cual podría admitir al menos actos de conservación del patrimonio. Sin embargo, y a la luz de derechos constitucionales tales como el de desarrollar cualquier actividad económica, resultaría plenamente admisible justificar que estas entidades especiales puedan incluso desarrollar tales actividades, al igual que las reguladas por el Código Civil. Por lo demás, y como se señaló, el carácter público que les corresponde, se explica por la forma de ser constituidas, esto es, por vía legal, y no por el objeto o finalidad de interés general que puedan atender, pues esto puede ser aspirado incluso por una de las entidades reguladas en el Título XXXIII del Libro I del Código Civil.

Todavía más, no existe impedimento legal en el sentido de que todas estas entidades tengan como única fuente de ingresos el desarrollo de actividades económicas. Eso sí, se debe respetar la relación de dicha actividad con sus fines, y además, debieren contar a lo menos con un capital inicial.

Con todo, la facultad de desarrollar actividades económicas lucrativas por parte de estas entidades, contiene una limitación fundamental, que no se encuentra presente en las sociedades que el Código Civil denomina de "industriales", y cuyo alcance ha sido objeto de constante confusión. La limitación consiste en la prohibición de que "las rentas, utilidades, beneficios o excedentes de la asociación no podrán distribuirse entre los asociados ni aún en caso de disolución" (art. 556 inciso tercero C.C.) ${ }^{20}$. En el mismo sentido, el artículo

\footnotetext{
20 Recuérdese que, en virtud de lo dispuesto en el artículo 563 del Código Civil, lo que se dispone en los artículos 549 hasta 561 acerca de las corporaciones y de los miembros que las componen, se aplicará a las fundaciones de beneficencia y a los individuos que las administran.
} 
557-2 del Código referido dispone que "las rentas que se perciban de esas actividades solo deberán destinarse a los fines de la asociación o fundación o a incrementar su patrimonio”.

Es necesario enfatizar que esta prohibición de distribuir las rentas a sus asociados o fundadores alcanza únicamente a las ganancias obtenidas por dichas entidades, en virtud del desarrollo de una actividad económica, como sería el caso de la venta de bienes, la organización de actividades o prestación de servicios, el rendimiento de bienes de capital, etc. De esta manera, una entidad podría distribuir todo o parte de su patrimonio compuesto por los aportes fundacionales, donaciones u otros ingresos distintos de las ganancias provenientes de una actividad económica, incluso a tales asociados o fundadores, o a cualquier persona, pues no existe norma prohibitiva al respecto ${ }^{21}$. Lo anterior podría ocurrir, por ejemplo, cuando se constituya una fundación para el beneficio de una familia o personas en particular, como se ha admitido en diversos ordenamientos jurídicos extranjeros.

Por su parte, la prohibición tampoco se extiende a la distribución de las rentas de estas entidades, a beneficiarios distintos de los asociados o fundadores.

Como corolario de lo dicho, es posible señalar que las fundaciones y corporaciones poseen una característica diferenciadora de las sociedades industriales, consistente en la prohibición concreta de distribuir directamente sus rentas, utilidades, beneficios o excedentes entre sus asociados o fundadores. Esta condición, es lo que debiere entenderse como "fin no lucrativo", y no la imposibilidad de realizar alguna actividad económica, ni menos de que su patrimonio pueda beneficiar económicamente a sus asociados o fundadores, directa o indirectamente, y en cualquier forma que no sea la distribución directa de sus ganancias, aunque no del resto de su patrimonio.

La definición de fin no lucrativo formulada, se apega al estricto tenor del sentido de los artículos 556 inciso tercero y 557-2 del Código Civil, el cual replica Lyon Puelma ${ }^{22}$. Incluso podría señalarse que este es un caso de coincidencia entre el sentido de la ley y el tenor literal de las palabras, dando lugar a una interpretación "declarativa", que fue justamente la hipótesis concebida por don Andrés Bello en el artículo 19 del Código Civil ${ }^{23}$.

De lo anterior, resulta la necesidad de distinguir entre el "fin lucrativo", explicado anteriormente a contrario sensu, del "ánimo de lucro", consistente este último en la intención de realizar una actividad económica con miras a obtener un beneficio, el cual puede o no ser distribuido a los propietarios, socios o accionistas, asociados o fundadores de cualquier persona jurídica. De esta manera, resulta que una fundación o asociación es una entidad sin fin lucrativo, en los términos antedichos, pero no obstante, puede tener un ánimo de lucro, en el caso de que decidiera emprender alguna actividad económica. Solo en el caso de las sociedades industriales, coexiste el fin y el ánimo lucrativo.

\footnotetext{
21 Las normas sobre disposición de los bienes que contemplan los artículos 438-2, letra f), y 561 del Código Civil, aplican una vez disuelta la entidad, y no debieran considerarse como una norma aplicable mientras esta exista legalmente, dado que resulta admisible que una asociación o fundación pueda procurar el beneficio particular, como se ha indicado en este trabajo.

22 Para LYON (2006) p. 92, el fin de lucro de las personas jurídicas se manifiesta "porque no pueden repartir las utilidades que obtengan de su actividad entre sus distintos socios o miembros". En un sentido similar IrRIBARRA (2014) p. 127.

23 Guzman (2011) p. 28.
} 
Por lo anterior, el ánimo de lucro no reflejaría "el propósito de los miembros de repartirse a título individual las ganancias obtenidas por la persona jurídica” según expone Alcalde ${ }^{24}$, sino que tal propósito refleja más bien su fin lucrativo.

\section{CRÍTICAS AL RAZONAMIENTO DE LA SENTENCIA}

La sentencia en análisis, comete la equivocación de no equiparar a entidades que realizan una misma actividad económica lucrativa, solo por razón de que una de ellas era una persona jurídica sin fines de lucro.

La Corte, incluso reconociendo que la fundación realiza una actividad económica, sostiene la disimilitud en que el lucro obtenido por ella "solo giraba en torno a lo necesario para proveer de materiales a más familias y en cierta forma poder ayudar con la venta de las mismas; y que no se pretendía obtener ganancias para lucrar, lo que sí persiguen los demás talleres artesanales, ya que es su fuente de sustento; es por esto que el comparar fundaciones con y sin fines de lucro no resulta homologable" 25 .

Al respecto, resulta absolutamente contradictoria la afirmación de que "no se pretendía obtener ganancias para lucrar", porque las ganancias no son otra cosa que lucro, ni tampoco dejan de serlo por la imposibilidad de ser distribuida a su fundador. Por otro lado, resulta inadmisible la afirmación de que una ganancia pueda no ser considerada como lucro, si es destinada a fines propios de una fundación o corporación, dado que una ganancia no depende de su destino para ser calificada como tal. Y por ello, las ganancias que respectivamente obtengan una entidad con y sin fines de lucro, constituyen rentas, y se afectan con la tributación general, sin distinciones de ninguna clase, ni menos exigencias como el destino aplicado a las mismas.

Así las cosas, si la exigencia del artículo 35 de la LIR es considerar un porcentaje de las ventas "entre contribuyentes que giren en el mismo ramo o en la misma plaza", la comparabilidad que el Servicio efectuó entre contribuyentes que giraban en el mismo ramo, debe versar sobre la identidad o similitud en la actividad económica desarrollada, y no en la calidad jurídica o finalidad lucrativa o no lucrativa de quienes la obtengan. Cumplida esta exigencia, como efectivamente sucedió en la especie, será posible luego incorporar matices para acercar la comparación, como podría ser el de considerar el tamaño de los contribuyentes comparados, la región en la que operen, sus respectivas posiciones en el mercado, costos de producción, riesgos y activos utilizados, etc. Por otro lado, la ley admitiría incluso la posibilidad de comparar entre contribuyentes que realicen actividades diversas, puesto que exige comparar aquellos que giren en el mismo ramo "o" en la misma plaza; es decir, en el primer caso, se exige que los sujetos de comparación realicen una misma actividad, mientras que en el segundo bastaría que se encuentren en una misma plaza o sitio, sin atender a una identidad o similitud en la actividad económica realizada. Este razonamiento tampoco se encontró presente en la sentencia analizada.

24 Alcalde (2015) p. 319.

25 Considerando Quinto de la sentencia. 
De todo lo dicho anteriormente, resulta incorrecta la afirmación de la Corte de que no son comparables los contribuyentes que realicen una misma actividad económica, solo en atención a la condición de tener o no un fin lucrativo. Por lo tanto, la Corte debió equiparar a ambos tipos de contribuyentes, dado que efectivamente cumplían con el presupuesto de la LIR, esto es, que giraban en el mismo ramo o actividad.

Un razonamiento correcto para resolver la litis, sería el de no calificar ex ante como incomparables u opuestos a entidades con y sin fines de lucro, pues al menos en materia de Impuesto de Primera Categoría, ello no tiene importancia, salvo que haya sido invocada alguna exención en particular, lo cual no ocurrió. A mayor abundamiento, el Servicio de Impuestos Internos ha interpretado sostenidamente que todas las personas, sean naturales o jurídicas, revisten la calidad de contribuyentes, en la medida que puedan estar sujetas a algunos de los tributos que establece la Ley de la Renta, lo cual ocurrirá en caso que tales personas posean bienes o realicen actividades susceptibles de generar rentas clasificadas en alguna de las categorías que contempla dicho texto legal. Asimismo, la Ley sobre impuesto a la renta, salvo las excepciones taxativas que ella misma establece, no atiende a la naturaleza o finalidad de las personas para gravarlas o no con impuesto, sino que considera las actividades que estas realizan, los actos y contratos que ejecutan y los beneficios económicos que puedan obtener ${ }^{26}$.

De esta manera, la jurisprudencia debiere aceptar la posibilidad de que una entidad sin fines de lucro pueda obtener rentas provenientes de actividades económicas, incluso más significativas que las obtenidas por una sociedad con fines lucrativos. Ello, básicamente porque el éxito en su actividad económica depende de otros factores que exceden la autorización o impedimento de distribuir sus rentas a sus propietarios.

La comprensión sobre el significado de que una fundación o corporación tenga o no fines de lucro, es una cuestión crucial para evitar desentendimientos a la hora de valorar su relación con el resto de los grupos intermedios, sean estos públicos o privados, y en particular, con la eficiencia de las diversas normas tributarias a las que son sujetos todos los contribuyentes. En la sentencia comentada, la errada comprensión sobre el alcance del lucro derivó en que la acción fiscalizadora del Servicio de Impuestos Internos fuere en vano, afectando su legítima expectativa de recaudación, y dejando a la fundación fiscalizada en una posición mejorada respecto de empresas que realizaban su misma actividad económica, y que debieron incurrir en sus obligaciones tributarias. Este desequilibrio, denominado como de "inequidad horizontal" en economía, ciertamente que constituye una infracción a la igualdad que la Constitución Política de la República asegura a todas las personas en el trato que deben dar el Estado y sus organismos en materia económica, así como también en la igual repartición de los tributos.

26 Ver Oficios SII N. ${ }^{\text {os }} 4.998$ de 2006, 3.623 de 2004, y 2169 de 2015. 


\section{CONCLUSIONES}

Las fundaciones y corporaciones constituyen grupos intermedios de importante valor para el desarrollo del bien común al cual somos llamados tanto el Estado como los particulares. Asimismo, estas entidades reflejan la importancia de la colaboración y la solidaridad, para la construcción de una sociedad más justa.

En el presente trabajo se expuso la imprecisión existente respecto de los fines que pueden alcanzar las fundaciones y las corporaciones, desmitificando la imposibilidad de que puedan satisfacer incluso intereses particulares, como asimismo, de que no puedan tener como beneficiarios a personas determinadas o determinables. En efecto, el artículo 545 inciso cuarto del Código Civil, permite que las fundaciones o corporaciones puedan compartir características comunes, de manera que una corporación podría tener fines de interés general, de la misma manera en que una fundación podría tener fines de interés particular. Así, resultaría admisible el reconocimiento de las denominadas fundaciones familiares, como sucede en diversas legislaciones extranjeras.

Asimismo, se precisó el alcance del fin no lucrativo de estas entidades, concluyéndose que este se acota estrictamente a la distribución directa de sus rentas o ganancias a sus asociados o fundadores, y no a la posibilidad de desarrollar alguna actividad económica, ni menos a que sus beneficiarios, cualesquiera que sean, puedan beneficiarse económicamente de sus recursos, de cualquiera otra forma que no sea la señalada, sea directa o indirectamente. Por lo mismo, resulta lícito que una de estas entidades, en armonía con sus fines, distribuya sus rentas a otros beneficiarios distintos de sus asociados o fundadores; o bien cuando entregue a estos últimos todo o parte de su patrimonio, excluidas sus rentas. Distinto del fin de lucro antedicho es el ánimo de lucro, que consiste en la legítima expectativa de obtener una ganancia por el desarrollo de una actividad económica, y que puede estar presente también en este tipo de entidades, en la medida de que se relacionen con sus fines.

En el caso de que una fundación o corporación decida realizar una actividad económica lucrativa, la ley tributaria la considera un contribuyente más, debiendo cumplir con sus obligaciones tributarias por las rentas obtenidas, de la misma manera en que lo hace un contribuyente con fines lucrativos, salvo que sea beneficiaria de alguna exención legal particular, que dicho sea de paso puede extenderse a cualquier tipo de contribuyente. Ello se debe a que en general, las normas tributarias atienden más a la actividad económica realizada, que a la calidad o limitaciones con las que cuenten.

Finalmente, el artículo 35 de la Ley sobre Impuesto a la Renta, obliga al Director Regional respectivo a tasar una base imponible en el caso de que la renta líquida imponible afecta al Impuesto de Primera Categoría no pueda determinarse. Uno de los métodos de tasación, consiste en considerar un porcentaje de las ventas realizadas durante el ejercicio, tomando como base, entre otros antecedentes, un promedio de los porcentajes obtenidos por este concepto o por otros contribuyentes "que giren en el mismo ramo". Al respecto, resulta objetable el razonamiento de la Corte Suprema de no reconocer como comparables entidades que realicen una misma actividad económica pero que se distingan simplemente porque una de ellas no puede distribuir sus rentas a sus asociados o fundadores. Al menos para efectos tributarios, y dado que sus normas se enfocan en la recaudación sobre rentas obtenidas por actividades económicas, la equiparación entre ambas entidades resulta ajustada a derecho, al cumplir cabalmente con las exigencias de comparabilidad del artículo 35 citado. 
La decisión de la Corte de no equiparar ambos tipos de contribuyentes, implicó incluso una inobservancia directa de las normas de interpretación legal, pues el artículo 35 no solo era clara en sus expresiones, sino también en su sentido.

Asimismo, resulta objetable que la Corte no califique como lucro a la ganancia obtenida por una fundación producto del desarrollo de una actividad económica, porque haya sido obtenida por una fundación, y además por el destino aplicado a tales recursos, esto es, para la concreción de sus fines de interés general. Dicha exigencia no existe en norma alguna, ni menos se contempla dentro las normas sobre determinación de la base imponible del Impuesto de Primera Categoría. Las ganancias y rentas son tales, con independencia de quién las haya generado, y también, del destino al cual sean aplicados.

\section{BIBLIOGRAFÍA CITADA}

AlCALDE, Jaime (2015): "Notas sobre el concepto de persona jurídica sin fines de lucro a propósito de la Ley 20.845 sobre inclusión escolar", Revista Chilena de Derecho Privado, $\mathrm{N}^{\circ}$ 25: pp. 315-333.

Alessandri, Arturo; Somarriva, Manuel y Vodanovic, Antonio (2009): Tratado de derecho civil, Tomo I (Santiago, Editorial Jurídica de Chile).

Bertelsen, Raúl (1991): "El derecho canónico ante la ley chilena, diócesis y asociaciones de fieles", Revista de Derecho de la Universidad Católica de Valparaíso, vol. XIV: pp. 473484 .

Claro, Luis (2013): Explicaciones de derecho civil chileno y comparado, Tomo II (Santiago, Editorial Jurídica de Chile).

Corral, Hernán (2014): "Constitucionalización del derecho civil, reflexiones desde el sistema jurídico chileno”, en Villabella, Pérez, Molina (edit.), Derecho Civil Constitucional (México, Grupo Editorial Mariel) pp. 1-16.

Guzmán, Alejandro (2011): Las reglas del Código Civil de Chile sobre interpretación de las leyes (Santiago, Abeledo Perrot).

IRribarra, Eduardo (2014): "Planificación tributaria sucesoria mediante fundaciones", Revista de Estudios Tributarios Universidad de Chile, vol. 10, N 10: pp. 123-148.

LyON, Alberto (2006): Personas Jurídicas (Santiago, Ediciones Universidad Católica de Chile, cuarta edición).

\section{NORMAS CITADAS}

Decreto Ley No 824 (31/12/1974), Ley sobre impuesto a la renta, Chile.

\section{JURISPRUDENCIA CITADA}

FundaCión SOLIDARIDAd CON SERVICIO DE IMPUestos INTERNos (2014): Primer Tribunal Tributario y Aduanero de Santiago, 12 de agosto de 2014 (acción de reclamación). 